(1)

CrossMark

\section{Correlation and causality: a COVID-19 conundrum}

To the Editor:

I read with interest the two contributions by J.D. Chalmers and co-workers to the July issue of the European Respiratory Journal. In a reply to correspondence concerning the inhaled corticosteroid withdrawal controversy in COPD [1], they suggest that A. Agusti succumbs to the fallacy of post hoc, ergo, propter hoc [2], i.e. A occurred, then B occurred: therefore, A caused B. However, as we know, correlation is not causality.

Yet, in their original research article, LONERgAn and ChALmers [3] perpetrate the same error in spades. They use the trajectory of deaths from coronavirus disease 2019 (COVID-19) from around the world to estimate the consequences of easing lockdown measures. They assume the current fall in the rate of COVID-19 related mortality is a consequence of lockdown; but is it? There is much we do not know about the virus, but if it behaves like other coronaviruses then there will be a marked seasonal variation [4]. Did Europe recover because sumer is icumen in?
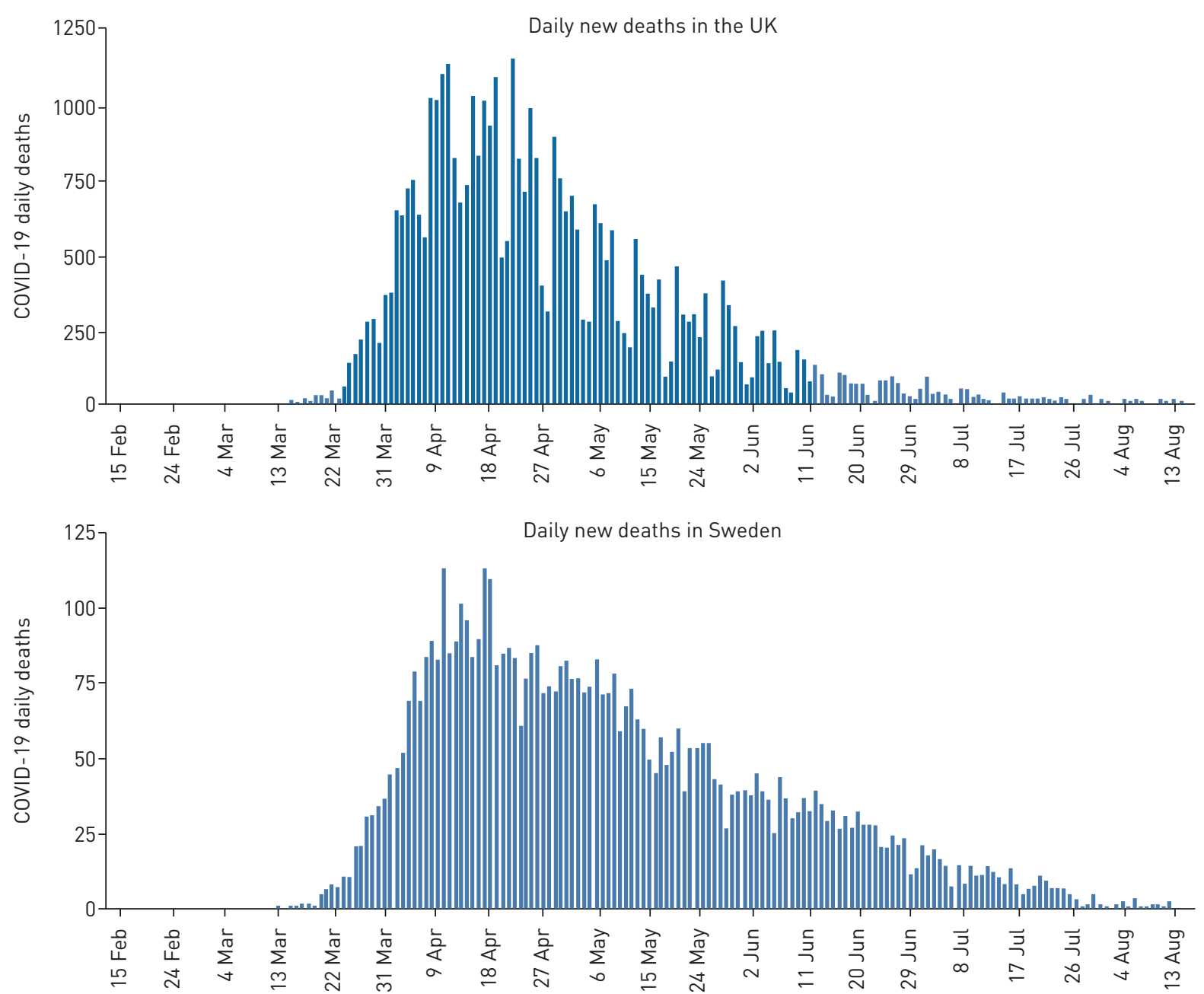
What we need is a control group. There is one European country where a much lighter application of social measures, well short of full lockdown, is practised. That is Sweden. If we compare by eye the weekly COVID-19-related mortality figures from Sweden with that of a similarly afflicted country, such as the UK, then in both countries there is a marked fall as spring turns into summer, albeit a bit slower in Sweden (figure 1).

If the mortality curves have a similar shape despite large differences in social measures adopted, then this must infer that such measures can only have had a minor effect on the epidemiology of this phase of the pandemic. It is surely incorrect to then to apply complex statistical modelling to mortality rates from 89 countries whose surety of data collection varies widely.

Lonergan and Chalmers [3] treat the reader to a detailed, and to me at least, indecipherable account of their "simple" modelling and its outcomes. The pitfalls of using such tools in COVID-19 research have been highlighted recently [5]. The results from the models used to predict the initial onslaught of the virus differed hugely, leading to panic buying of ventilators and the creation of overflow (Nightingale in the UK) hospitals which were never used. Even the best model is prey to the assumptions made in its construction. The belief that we know the contribution that social measures have made to the evolution of the pandemic is wrong and so advising "[our] estimates are incompatible with a return to previous activities post 'lockdown"” is hubris which may have greater socioeconomic and, thus, clinical consequences than the virus itself.

@ERSpublications

Predictive models depend heavily on the assumptions made in their construction https://bit.ly/2Eex05F

Cite this article as: Morice AH. Correlation and causality: a COVID-19 conundrum. Eur Respir J 2020; 56: 2003174 [https://doi.org/10.1183/13993003.03174-2020].

\section{Alyn H. Morice}

Hull York Medical School, University of Hull, Hull, UK.

Correspondence: Alyn H. Morice, Castle Hill Hospital, Cottingham, HU16 5JQ, UK. E-mail: a.h.morice@hull.ac.uk

Received: 17 Aug 2020 | Accepted: 17 Aug 2020

Conflict of interest: A.H. Morice has nothing to disclose.

\section{References}

Agusti A. Withdrawal of inhaled corticosteroids in COPD. Eur Respir J 2020; 56: 2001684.

Chalmers JD, Miravitlles M. Withdrawal of inhaled corticosteroids in COPD. Eur Respir J 2020; 56: 2001778.

Lonergan M, Chalmers JD. Estimates of the ongoing need for social distancing and control measures post-"lockdown" from trajectories of COVID-19 cases and mortality. Eur Respir J 2020; 56: 2001483.

4 Raoult D, Zumla A, Locatelli $\mathrm{F}$, et al. Coronavirus infections: epidemiological, clinical and immunological features and hypotheses. Cell Stress 2020; 4: 66-75.

5 Holmdahl I, Buckee C. Wrong but useful - what Covid-19 epidemiologic models can and cannot tell us. N Engl J Med 2020; 383: 303-305. 